\title{
COMPETÊNCIAS DO NÍVEL DE COMANDO DE UM ÓRGÃo PÚBLICO MUNICIPAL
}

Lucileila do Rosário Queiroz (Sumaré Centro Universitário) lucileila.queiroz@ sumare.edu.br Roberto Kanaane (Centro Paula Souza) kanaanhe@gmail.com

\section{Resumo}

O objetivo deste artigo caracterizou-se pela identificação do quadro de competências gerenciais dos servidores que ocupam cargos de comando de uma Subprefeitura da Cidade de São Paulo. Foi realizada pesquisa quantiquali, com abordagem descritiva conjugada com estudo de caso. Os dados empíricos foram coletados por meio de observação participante e aplicação de dois questionários semiestruturados e embasados no referencial teórico e nos objetivos da pesquisa. Como resultado identificou-se que: das 17 competências gerenciais analisadas, o nível de comando possui duas, "aprender a aprender" e "vitalidade"; o que sugere que ações estratégicas sejam mobilizadas no intuito de ampliar as competências dos gestores, visando implementar ações proativas e os respectivos impactos na Instituição.

Palavras-chaves: Sistemas Produtivos; Administração pública; Gestão por competências no setor público; Competências gerenciais e individuais.

\section{Introdução}

A Administração Pública é constituída por órgãos a serviço do Estado (SIGOLLO; SOARES, 2013) e tem por atribuições gerir os bens públicos e interesses das pessoas de uma determinada comunidade. No entanto, a percepção da sociedade sobre os serviços públicos prestados é de que não possuem qualidade (SALES, 2010), são ineficientes e onerosos, os recursos são desperdiçados, os bens públicos são tratados com desmazelo, os servidores públicos são descompromissados, além de não haver planejamento, controle, coordenação ou transparência (RIBEIRO; MANCEBO, 2013).

Por outro lado, as mudanças tecnológicas, econômicas, políticas e sociais vem transformando as relações em todo o mundo (em virtude da globalização e do nível de complexidade existente nas sociedades e consequentemente nas organizações) e têm contribuído para a necessidade de aperfeiçoamento dos modelos de gestão dos órgãos públicos, tendo em vista a perspectiva de atingir melhores resultados e prestar um serviço público com qualidade (GLÓRIA JR., 2012; MOURA; SOUZA, 2016; SIGOLLO; SOARES, 2013). 
A gestão por competências tem sido evidenciada pela literatura científica, como estratégia assertiva para alavancar a gestão de pessoas com foco no desempenho individual e coletivo visando a efetiva prestação dos serviços.

O Sistema de Gestão por Competência refere-se a

uma ferramenta gerencial que apoia o planejamento, o monitoramento e a avaliação
das ações de desenvolvimento a partir da identificação dos conhecimentos, das
habilidades e das atitudes necessárias ao desempenho das funções e as lacunas a
serem superadas pelos servidores (MARQUES, 2013, p. 6).

Neste sentido, há uma tendência que destaca a Gestão por Competências como uma prática que engloba o planejamento, a captação, o desenvolvimento e a avaliação das pessoas, em todos os níveis (individuais, gerenciais, coletivos e organizacionais), levando-se em consideração o conjunto de capacidades, habilidades e comportamentos que os funcionários precisam ter para a plena execução de suas atividades (BAHRY; BRANDÃO, 2005). Tal estratégia vem sendo disseminada no intuito de contribuir para a eficiência e eficácia organizacional.

Carbone et al (2009, p. 50) salientam que "a gestão por competências, [...] propõe-se a alinhar esforços para que as competências humanas possam gerar e sustentar as competências organizacionais necessárias à consecução dos objetivos estratégicos da organização".

As organizações públicas têm a responsabilidade de bem gerir o dinheiro público, "gastando de forma mais criteriosa e responsável os recursos públicos, visando atender precípua e estrategicamente às demandas da população" (PINHEIRO; SILVA, 2012, p. 199). Assim, a gestão por competências apresenta-se como uma estratégia contemporânea de gerenciamento de pessoas, visando a qualificação dos servidores e a melhoria dos resultados organizacionais na prestação dos serviços públicos.

Em função do exposto, o presente estudo visa caracterizar o quadro de competências gerenciais dos servidores do nível de comando de uma Subprefeitura, consideradas pela literatura pertinente ao tema, essenciais ao alcance do efetivo desempenho gerencial.

\section{Gestão por competências}

A gestão por competências contempla, entre outros pontos, ações voltadas ao planejamento, captação, desenvolvimento e avaliação das pessoas, nos níveis individuais, coletivos, gerenciais e organizacionais, de acordo com o conjunto de capacidades, habilidades e 
comportamentos que os indivíduos necessitam possuir para a execução de suas atividades e alcance dos objetivos organizacionais (BAHRY; BRANDÃO, 2005; SILVA; MELLO, 2013).

Mello e Silva (2013) defendem que na gestão por competências não importa somente identificar os conhecimentos que o indivíduo possui, mas sim a aptidão que ele apresenta para utilizar esses conhecimentos na resolução de problemas, com foco no alcance de resultados. Argumentam ainda que não há separação entre competência e ação.

Segundo Marques (2013, p. 6), Sistema de Gestão por Competência é uma "ferramenta gerencial que apoia o planejamento, o monitoramento e a avaliação das ações de desenvolvimento a partir da identificação dos conhecimentos, das habilidades e das atitudes necessárias ao desempenho das funções e as lacunas a serem superadas pelos servidores".

A organização precisa mapear quais são as competências que seus funcionários necessitam para contribuir com o alcance dos objetivos organizacionais, além de diagnosticar também quais as competências existentes. A diferença entre as competências existentes e as necessárias, caracteriza-se como sendo lacunas de competências, ou ainda gap de competências. Os objetivos organizacionais necessitam decorrer das estratégias, que foram definidas com base na missão, visão e valores organizacionais (BAHRY; BRANDÃO, 2005; CARBONE et al, 2009; PANTOJA et al, 2012).

Identificado o gap de competências, é necessário empenho por parte da organização para desenvolvê-las internamente e/ou externamente via treinamento e desenvolvimento (CARBONE et al, 2009).

A gestão de competências tende a ser um sistema cíclico e contínuo, que implica em considerar as estratégias, objetivos e metas organizacionais, definidas periodicamente.

\subsection{Competências}

A gestão por competências implica na compreensão do que se concebe por competências. Entretanto, não há um consenso sobre o que vem a ser competência, pois os autores que investigam o assunto tendem a delimitar o seu significado, levando em consideração uma série de indagações, tendo em vista o contexto de análise e sua aplicação prática (BÜNDCHEN; ROSSETTO; SILVA, 2011).

Os estudos sobre competência individual surgiram nos Estados Unidos e na França. No Brasil, os autores Fleury (2002), Dutra (2004) e Meister (2005) foram os pioneiros em revisar 
os conceitos de competência e sob influência dos norte-americanos e franceses buscaram concepções contemporâneas, mais aplicáveis ao contexto nacional.

Para Fleury (2002), o conceito de competência engloba as capacidades do indivíduo em saber agir com responsabilidade diante das situações nas quais está inserido. Essa aptidão (do saber agir) necessita ser reconhecida pelos pares e engloba a mobilização, integração e transferência de conhecimentos, recursos e habilidades, contribuindo para a agregação de valores econômico à organização e social à pessoa.

Segundo Dutra (2004), competência abrange o conjunto de conhecimentos, habilidades e atitudes de um indivíduo, associados à capacidade de entregá-las à organização, fazer o que se espera e o que é necessário que se faça.

Para Meister (2005), existe um conjunto de competências básicas que os empregados necessitam possuir para que a organização consiga apresentar um bom desempenho e superar seus concorrentes. Essas competências são: aprender a aprender, comunicação e colaboração, raciocínio criativo e resolução de problemas, conhecimento tecnológico, conhecimento de negócios globais, desenvolvimento de liderança e autogerenciamento da carreira.

Além das competências individuais, os empregados precisam possuir competências que facilitem seu relacionamento com os demais integrantes da equipe, chamadas de competências coletivas.

\subsection{Competências gerenciais}

A responsabilidade quanto ao envolvimento e engajamento das pessoas está vinculada ao papel dos gestores. A estes, por sua vez não basta apenas serem detentores de amplas competências técnicas, ou seja, é necessário que tenham competências no relacionamento interpessoal e conhecimento das pessoas com as quais trabalham para estimular as potencialidades de cada indivíduo e canalizá-las ao trabalho em equipe, contribuindo para o alcance de resultados positivos. Santos, Caetano e Jesuíno (2012) afirmam que a liderança é um aspecto importante, pois tende a influir nos processos de trabalho e nos resultados das equipes.

Ao gestor se concebe o papel de facilitador do trabalho da equipe, cabendo-lhe solucionar conflitos, criar alternativas motivacionais dos colaboradores, ampliar espaços para que as pessoas possam expressar seus pensamentos e incentivar a busca coletiva de soluções aos 
problemas organizacionais, visando o alcance dos objetivos organizacionais (FERREIRA; KANAANE; SEVERINO, 2010; SANTOS; CAETANO; JESUÍNO, 2012).

Entende-se que a principal atribuição do líder é articular os diversos membros da equipe, integrando as atividades exercidas, com foco no alcance de resultados, o que requer dos gestores possuir as respectivas competências: aprender a aprender, criar visões compartilhadas, planejar e conduzir transições, colaboração ambiental, análise organizacional, configuração organizacional, potencialização de si e dos outros e vitalidade; posicionamento da empresa, identificar mudanças externas, integrar a equipe, avaliar pessoas, moldar equipes, estabelecer objetivos, fixar prioridades e enfrentar forças externas (FERREIRA; KANAANE; SEVERINO, 2010; KANAANE, 2013; KANAANE; ORTIGOSO, 2010; GAMEIRO, 2012; MOSCOVICI, 1988; SPENCER; PRUSS, 1994).

\subsection{Competências de gestão no setor público}

O modelo gerencial contemporâneo tem solicitado aos gestores alternativas de ação que incentive a qualidade e amplie a prestação dos serviços públicos. A gestão por competências apresenta-se como uma estratégia necessária para gerir o desempenho dos servidores com intuito de atingir a eficiência e os resultados na prestação de serviços.

Para viabilizar a implantação da gestão por competências no serviço público, a União editou o Decreto $n^{\circ}$ 5.707/06, (posteriormente alterado pelo Decreto 9.991/19), que instituiu a Política Nacional de Desenvolvimento de Pessoal - PNDP. A PNDP é a referência existente na área de gestão de pessoas para os órgãos públicos, visando a sua implementação nos órgãos da administração pública federal direta, autarquias e fundações públicas (SILVA; MELLO, 2013). Tem-se constatado que está atuando, também, como parâmetro para os órgãos estaduais e municipais.

A partir do instrumento normativo, os órgãos da administração pública federal utilizam a gestão por competências para planejar, executar e avaliar as ações de capacitação, além de implementar o planejamento de pessoal, a gestão de recrutamento e a avaliação de desempenho, visando inclusive, otimizar melhorar a qualidade da prestação dos serviços públicos à sociedade (PANTOJA et al, 2012).

Pantoja et al (2012), afirmam que a PNDP demandou a necessidade de construir novos perfis de qualificação profissional necessários à transformação de um sistema baseado em normas regulamentares e procedimentos administrativos para um modelo de gestão com foco em 
resultados. Assim, "a ênfase no desenvolvimento estratégico de servidores possibilita a relação da PNDP com as perspectivas teóricas de gestão estratégica de pessoas (GEP), as quais preveem o alinhamento dos processos de gestão de pessoas e das competências dos indivíduos à estratégia organizacional” (FONSECA et al, 2013, p. 1452).

O modelo de gestão por competências, assim como os objetivos estratégicos do órgão público atuam como parâmetro para a definição das competências necessárias ao seu alcance. Consequentemente, identifica-se as competências existentes e as necessárias, traçando-se um plano de desenvolvimento de competências voltado aos servidores (MOURA; SOUZA, 2016; SILVA; MELLO, 2013).

Segundo Pantoja et al (2012), embora o modelo de gestão tenha por objetivo melhorar a qualidade e eficiência dos serviços públicos, poucos são os órgãos que conseguiram implementá-lo. Nesse sentido, Moura e Souza (2016) fundamentam que a implantação da gestão por competência implica numa ruptura com os paradigmas em gestão até então existentes, como padrões gerenciais, traços culturais e a própria formação histórica da administração pública.

Nesse sentido, o mapeamento e o estudo das competências do nível de comando em uma instituição pública no município de São Paulo, buscou angariar dados sob a ótica dos gestores e funcionários a eles subordinados, traçando um prisma das competências emergentes dos gestores. A seguir os procedimentos metodológicos.

\section{Procedimentos Metodológicos}

O estudo foi realizado em uma das 32 (trinta e duas) Subprefeituras da Cidade de São Paulo. A Subprefeitura é um órgão da administração direta da Prefeitura de São Paulo, criada segundo a Lei 13.399/2002. Compõe-se de um complexo de atividades de serviços públicos destinados a atender à população local nas suas necessidades, dentre elas: a democratização da gestão pública; o planejamento, execução e controle dos sistemas locais; a promoção do desenvolvimento a partir da implementação de políticas públicas definidas pela instância central da administração; a ampliação e melhoria da qualidade dos serviços públicos, envolvendo as competências.

A relevância do objeto de estudo repousa na possibilidade em verificar as competências gerenciais apontadas pela literatura científica presentes e necessárias aos gestores públicos. 
Foi realizada pesquisa qualitativa e quantitativa, com abordagem descritiva, conjugada com estudo de caso. A pesquisa descritiva busca especificar as propriedades relevantes de pessoas, grupos, comunidades ou qualquer outro fenômeno que seja submetido a análise (SAMPIERI; COLLADO; LUCIO, 2006).

Quanto à fundamentação teórica, utilizou-se pesquisa bibliográfica, documental e a legislação disponível. Pesquisa bibliográfica "é o estudo sistemático desenvolvido com base em material publicado em livros, revistas, jornais, redes eletrônicas, isto é, material acessível ao público em geral" (VERGARA, 2014, p. 43), enquanto a investigação documental referiu-se aos documentos existentes nas instituições públicas e/ou privadas (VERGARA, 2014).

Os dados empíricos foram coletados pela utilização de observação participante. Segundo Silva (1986, p. 828), observação participante "consiste no fato de que o pesquisador passa a fazer parte do grupo estudado a fim de observar os fenômenos sociais". Foram adotados também dois questionários.

$\mathrm{O}$ primeiro instrumento de pesquisa continha perguntas de auto-avaliação, onde o próprio servidor que compõe o nível de comando da organização, assinalou o grau de "importância" das competências gerenciais para o desempenho de suas funções, bem como o grau de "domínio" de cada competência. O segundo, mensurou a percepção dos subordinados, (também relacionada aos dois critérios, "domínio" e "importância”) quanto as competências gerenciais de sua chefia imediata.

A elaboração das questões, do instrumento de pesquisa, foi constituída considerando-se as competências gerenciais indicadas por Kanaane (2013), Kanaane e Ortigoso (2010), Moscovici (1998), Spencer e Pruss (1994) e Gameiro (2012), pesquisadores/estudiosos da área de gestão de pessoas.

Foram distribuídos 119 questionários, tendo obtido resposta de 108 pessoas, correspondendo a 90,76\%. Destes, 30 foram respondidos pelos ocupantes dos cargos de comando $(27,8 \%)$ e 78 pelos subordinados $(72,2 \%)$.

As respostas aos questionários foram tabuladas e calculadas a média referente a cada uma das competências pesquisadas. Segundo Vieira (2013, p. 38), a "média de um conjunto de dados é obtida somando todos os dados e dividindo o resultado pelo número deles".

Critérios de evidenciação das competências: 
I. A escala de graduação das respostas $(1=$ não domina a competência; $2=$ tem pouco domínio; 3 = tem médio domínio; 4 = tem alto domínio; e 5 = tem domínio completo); considerou-se como existentes as competências cuja média resultou entre 4 e 5; as que apresentaram média inferior a 4 foram consideradas como não dominadas, demandando desenvolvimento (GLÓRIA JR., 2012);

II. Adotou-se como referência a posição de Carbone, et al, 2009 para aferir "a relação entre a carência (por parte da pessoa) de determinada competência e a importância dessa competência para o papel ocupacional ou para o contexto organizacional no qual a pessoa está inserida" (CARBONE et al, 2009, p. 68); bem como mapear o gap de competências, adotou-se a equação: N = I (4 - D), apresentada por Carbone et al (2009), onde N representa a lacuna, I o grau de importância e D o grau de domínio da competência. Neste estudo, para o cálculo da equação foram considerados como valores de I e D, a média dos resultados das respostas respectivas. Quanto maior o $\mathrm{N}$, maior o gap e, consequentemente, maior a necessidade de desenvolver a competência; se o $\mathrm{N}$ for igual a 0 , significa que não há lacuna na competência, ou seja, a competência é considerada como dominada.

III. Com relação à "importância", foi considerada a escala do instrumento de pesquisa: $1=$ nenhuma importância; 2 = pouca importância; 3 = média importância; 4 = alta importância; e 5 = extrema importância, ou seja, a competência cuja média aritmética do grau de importância se situou entre 4 e 5 foi considerada como "necessária" ao nível de comando; se o valor resultou igual a 5 significa que a competência foi entendida como "imprescindível" (GLÓRIA JR., 2012).

\section{Resultados e Discussões}

Aplicando-se os critérios I e II de evidenciação do domínio das competências, os dados da pesquisa informam na figura 1 que, das 17 competências gerenciais, o nível de comando possui duas, "aprender a aprender" e "vitalidade". Constatou-se assim, que para a melhoria dos resultados organizacionais é necessário minimizar o gap de competências, por meio de um plano de desenvolvimento, haja vista que das 17 competências investigadas, 15 necessitam ser aperfeiçoadas, pois não são dominadas pelo nível de comando.

Figura 1 - Comparação entre os graus de "domínio" e "importância" 


\begin{tabular}{|c|c|c|c|}
\hline Competências Gerenciais & $\mathbf{D}$ & $\mathbf{I}$ & $\mathbf{N}$ \\
\hline Configuração organizacional & 3,6 & 4,4 & 1,68 \\
\hline Identificar mudanças externas & 3,6 & 4,3 & 1,54 \\
\hline Estabelecer objetivos & 3,7 & 4,4 & 1,46 \\
\hline Avaliar as pessoas & 3,7 & 4,4 & 1,41 \\
\hline Envolver a equipe & 3,7 & 4,4 & 1,30 \\
\hline Desenvolver equipes & 3,7 & 4,4 & 1,18 \\
\hline Criar visões compartilhadas & 3,7 & 4,4 & 1,12 \\
\hline Enfrentar forças externas & 3,8 & 4,4 & 1,09 \\
\hline Posicionar a unidade/departamento & 3,8 & 4,4 & 0,90 \\
\hline Análise organizacional & 3,8 & 4,6 & 0,72 \\
\hline Planejar e conduzir transições & 3,9 & 4,4 & 0,67 \\
\hline Potencialização de si e dos outros & 3,9 & 4,5 & 0,58 \\
\hline Fixar as prioridades & 3,8 & 4,5 & 0,54 \\
\hline Integrar a equipe & 3,9 & 4,6 & 0,51 \\
\hline Colaboração ambiental & 3,9 & 4,4 & 0,25 \\
\hline Aprender a aprender & 4,0 & 4,6 & 0 \\
\hline Vitalidade & 4,2 & 4,5 & $-0,84$ \\
\hline
\end{tabular}

Fonte: Dados da pesquisa

Quanto ao grau de importância, aplicando-se o critério III de evidenciação das competências, percebeu-se que todas as 17 competências gerenciais foram consideradas pelos respondentes como "necessárias", apresentando resultados de média entre 4 e 5 (figura 1). Este resultado permite aferir que as competências consideradas essenciais pelos autores do tema "gestão por competências" e que embasaram o referencial teórico deste estudo, também foram consideradas pelos respondentes da pesquisa como necessárias ao alcance de um alto desempenho.

No tocante ao quadro geral de competências evidenciadas no estudo, concebe-se que os resultados sinalizaram a possibilidade de implementar ações que vão ao encontro de programas de desenvolvimento gerencial, contemplando a atuação dos componentes do comportamento gerencial, como conhecimentos gerenciais e organizacionais e habilidades administrativas. Ao mesmo tempo fica evidente que as competências interpessoais se fazem necessárias para implementação do desenvolvimento dos gestores.

\section{Conclusões}


A viabilidade de implementação da gestão por competência no setor público, como estratégia para melhoraria dos resultados organizacionais foi o que motivou a realização deste estudo. Nesse sentido, o presente trabalho teve como objetivo: "caracterizar o quadro de competências gerenciais dos servidores do nível de comando da Subprefeitura, consideradas pela literatura científica pertinente ao tema, essenciais ao alcance de um efetivo desempenho". Para tanto realizou-se levantamento bibliográfico sobre gestão por competências, onde foram identificadas quais as competências gerenciais que os pesquisadores do tema consideram fundamentais à obtenção de uma alta performance.

Posteriormente, passou-se ao desenvolvimento da pesquisa de campo, visando verificar a percepção que os servidores têm acerca das competências gerenciais dos ocupantes de cargos de chefia.

As respostas sinalizaram como resultado que, embora todas as 17 competências gerenciais estudadas tenham sido consideradas como "necessárias" aos ocupantes do nível de comando, para que a organização melhorasse seus resultados, o nível de comando da Subprefeitura possui duas competências desenvolvidas, "aprender a aprender" e "vitalidade", caracterizando o quadro geral comportamental dos gestores envolvidos. O que sugere a perspectiva de programas de desenvolvimento de postura do gestor público, o que contribuirá para ampliar o escopo de excelência desta categoria profissional.

Sugere-se para pesquisas futuras, investigar outras Subprefeituras da Cidade de São Paulo, além de outros órgãos de esferas políticas distintas, Estaduais e/ou Federais, com o intuito de compreender o contexto vigente no serviço público quanto a postura dos gestores, e ampliar o rol de análise. Tal investigação requer a aferição da percepção dos superiores e pares, com a finalidade de estender o mapeamento a todos os servidores da organização, visando estabelecer diretrizes e táticas voltadas ao dimensionamento das competências dos gestores das respectivas Subprefeituras, tendo em vista os impactos nos resultados decorrentes das demandas e necessidades emergentes da comunidade, ou seja, os munícipes, frente aos serviços públicos e o papel político-social exercido pelos respectivos órgãos.

\section{REFERÊNCIAS}

BAHRY, Carla P.; BRANDÃO, Hugo. P. Gestão por competências: métodos e técnicas para mapeamento de competências. Revista do Serviço Público, p. 179-194, abr-jun. 2005.

BRASIL. Decreto 5.707, de 23 de Fevereiro de 2006. Institui a Política e as Diretrizes para o Desenvolvimento de Pessoal da Administração Pública Federal Direta, Autárquica e Fundacional. Disponível em: 
<http://www.planalto.gov.br/ccivil_03/_Ato2004-2006/2006/Decreto/D5707.htm>. Acesso em 04 fev. 2020.

BRASIL. Decreto 9.991, de 28 de Agosto de 2019. Dispõe sobre a Política Nacional de Desenvolvimento de Pessoas da Administração Pública Federal Direta, Autárquica e Fundacional. Disponível em:

<http://www.planalto.gov.br/ccivil_03/_Ato2019-2022/2019/Decreto/D9991.htm\#art35>. Acesso em 04 fev. 2020.

BÜNDCHEN, Edson; ROSSETTO, Carlos R.; SILVA, Anielson B. Competências Gerenciais em Ação - O Caso do Banco do Brasil. REAd, ed. 69, vol. 17, n. 2, p. 396-423, mai-ago. 2011.

CANFILD, Anderson A. Uma Nova Ótica nos Relacionamentos Interpessoais. Centro Tecnológico OPET, v. 5, n.2, p. 14-15. Curitiba, 2005. Disponível em <http://www.comportamento.com.br/site2015_pt/936-2/>. Acesso em: 26 maio 2016.

CARBOnE, Pedro P. et al. Gestão por Competências e Gestão do Conhecimento. Rio de Janeiro: FGV, 2009.

Definição de Prebenda. Disponível em <http://www.dicionario-aberto.net/dict.pdf>. Acesso em: 21 set. 2016.

DUTRA, Joel S. Competências: Conceitos e Instrumentos para a Gestão de Pessoas na Empresa Moderna. São Paulo: Atlas, 2004.

FERREIRA, Maria G.; KANAANE, Solange; SEVERINO, Fátima R. Aspectos Comportamentais na Gestão de Pessoas. In: KANAANE, Roberto; FIEL FILHO, Alécio; FERREIRA, Maria G. (Org.). Gestão Pública:

Planejamento, Processos, Sistemas de Informação e Pessoas. São Paulo: Atlas, 2010.

FLEURY, Maria T. L. A Gestão de Competência e a Estratégia Organizacional. In: FLEURY, M. T. L. (org.). As Pessoas na Organização. São Paulo: Editora Gente, 2002.

FONSECA, Diogo R. et al. Autonomia para Gestão Estratégica de Pessoas no Setor Público Federal: Perspectivas de Análise e Agenda de Pesquisa. Revista de Administração Pública, v. 47, n. 6, p. 1451-1476, 2013.

GAMEIRO, Ricardo A. As 8 Competências Essenciais no Século 21. Época Negócios, fev, 2012. Disponível em <http://epocanegocios.globo.com/Revista/Common/0,,EMI21920-16642,00-

COMPETENCIAS+ESSENCIAIS+NO+SECULO.html>. Acesso em: 21 maio 2016.

GLÓRIA JR., Odair S. Competências e Habilidades Relevantes para um Chefe de Unidade Descentralizada de Perícia da Polícia Federal. Dissertação de Mestrado, FGV/RJ, 2012.

KANAANE, Roberto. Comportamento Humano nas Organizações: o Homem Rumo Ao Século XXI. $2^{\mathrm{a}}$ ed. São Paulo: Atlas, 2013.

KANAANE, Roberto.; ORTIGOSO, Sandra A. F. Manual de Treinamento e Desenvolvimento do Potencial Humano. São Paulo: Atlas, 2010.

MARQUES, Fernanda. Guia de Mapeamento e Avaliação de Competências para a Administração Pública Poder Executivo. Brasília, jun. 2013. Disponível em

<http://www.gespublica.gov.br/sites/default/files/documentos/guia_de_referencia_pratico-mapeamento-14-0813.pdf >. Acesso em: 21 maio 2016.

MEISTER, Jeanne C. Educação Corporativa: a gestão do Capital Intelectual Através das Universidades Corporativas. São Paulo: Person Makron, 2005.

MELlO, José A. C.; SILVA, Sheila A. P. S. Competências do Gestor de Academias Esportivas. Motriz, Rio Claro, v.19 n.1, p.74-83, jan./mar. 2013.

MOSCOVICI, Fela. Renascença Organizacional. RJ. LTC - Editora Ltda, 1988.

MOURA, Ana L. N.; SOUZA, Bruno C. Gestão Estratégica de Pessoas na Administração Indireta do Setor Público Federal: na Prática, ainda um Discurso. Revista do Serviço Público, v. 67, n. 4, p. 575-602, 2016. 
PANTOJA, Maria J. et al. Política Nacional de Desenvolvimento de Pessoal na Administração Pública Federal: uma Caracterização da Capacitação por Competências na Administração Pública Federal. In: Anais do V Congresso Conselho Nacional de Secretários de Estado da Administração de Gestão Pública, 2012.

PINHEIRO, Marcelo T.; SILVA, Monica A. R. Contribuições do escritório de Gerenciamento de Projetos Públicos na Gestão para Resultados. Revista do Serviço Público, v. 63, n. 2, p. 199-215, 2012.

RIBEIRO, Carla V. S.; MANCEBO, Deise. O servidor público no mundo do trabalho do século XXI. Psicologia: Ciência e Profissão, v. 33, n. 1, p. 192-207, 2013.

SALES, Ulisses. (Coordenador). Administração Gerencial: uma Revolução na Área Pública. São Paulo: Ripress, 2010.

SAMPIERI, Roberto H.; COLLADO, Carlos F.; LÚCIO, Pilar B. Metodologia de la Investigación. 4. ed. México: Mc Graw-Hill, 2006.

SANTOS, Joaquim; CAETANO, Antonio; JESUÍNO, Jorge C. As competências Funcionais dos Líderes e a Eficácia das Equipas. Revista Portuguesa e Brasileira de Gestão, v. 11, n. 2-3, p. 95-106, 2012.

SÃO PAULO. Lei Municipal $\mathbf{n}^{\circ} 13.399$ de $1^{\circ}$ de agosto de 2002. Dispõe Sobre a Criação de Subprefeituras no Município de São Paulo, e dá Outras Providências. Disponível em: <http://www.prefeitura.sp.gov.br/cidade/upload/lei_13_399_1254940922.pdf>. Acesso em: 03 jun. 2017.

SIGOLLO, Walter; SOARES, Maria T. R. Os Avanços e Caminhos do Desenvolvimento de Pessoas na Área Pública. In: BOOG, G. G.; BOOG M. (Coordenadores) Manual de Treinamento e Desenvolvimento: Gestão e Estratégia. São Paulo: Pearson Education do Brasil, 2013.

SILVA, Benedito. Dicionário de Ciências Sociais. Rio de Janeiro: Editora da FGV, 1986.

SILVA, Francielle M.; MELLO, Simone P. T. A Implantação da Gestão por Competências: Práticas e Resistências no Setor Público. Revista Eletrônica de Administração e Turismo-ReAT, v. 2, n. 1, p. 110-127, jan-jun. 2013.

SPENCER, John; PRUSS, Adrian. Gerenciando sua Equipe. São Paulo: Siciliano, 1994.

VERGARA, Sylvia C. Projetos e Relatórios de Pesquisa em Administração. 15. ed. São Paulo: Atlas, 2014.

VIEIRA, Sonia. Estatística Básica. São Paulo: Cengage Learning, 2013. 